\title{
Effectiveness is the gold standard of clinical research
}

\author{
Francesco Gazzillo, ${ }^{1}$ Adriano Schimmenti, ${ }^{2}$ Ivan Formica, ${ }^{3}$ Alessandra Simonelli, ${ }^{4}$ Sergio Salvatore ${ }^{5}$
}

${ }^{1}$ Department of Dynamic and Clinical Psychology, Sapienza University of Rome; ${ }^{2}$ Faculty of Human and Social Sciences, Kore University of Enna; ${ }^{3}$ Department of Psychological and Pedagogical Sciences and Cultural Studies, University of Messina; ${ }^{4}$ Department of Developmental and Socialization Psychology, University of Padua; ${ }^{5}$ Department of History, Society and Human Studies, University of Salento, Lecce, Italy

Psychological treatments have been shown to be at least as effective (and sometime even more effective) than psychotropic medications for many psychiatric disorders, in particular anxiety disorders, depressive disorders, and personality disorders (American Psychological Association, 2013; Cuijpers, 2017).

Effective psychological treatments are also cost-effective: their implementation in public mental health services is convenient in financial terms, with decades of studies consistently demonstrating a reduction in public spending for psychological health (Abbass, Kisely, Rasic, Town \& Johansson, 2015). Therefore, it could be critical that psychological treatments whose efficacy is supported by strong empirical evidence can be delivered as a primary choice in public mental health services. We hope and believe that the time when a psychologist or a psychiatrist (especially if paid by the public mental health system) could provide any treatment he or she thought fit, even in

Correspondence: Sergio Salvatore, Department of History, Society and Human Studies, University of Salento, Lecce, Italy.

Email: sergio.salvatore65@me.com

Acknowledgments: this article has been discussed and agreed with the members of the Board of Professors and Researchers of the Italian Academy's Dynamic Psychology Scientific Area. However, the Authors assume full responsibility for its content.

Key words: Effectiveness; Gold standard; Clinical research; Psychotherapy.

Citation: Gazzillo, F., Schimmenti, A., Formica, I., Simonelli, A., \& Salvatore, S. (2017). Effectiveness is the gold standard of clinical research. Research in Psychotherapy: Psychopathology, Process and Outcome, 20(2), 153-155. doi: 10.4081/ripppo.2017.278

Received for publication: 15 May 2017

Accepted for publication: 4 July 2017.

This work is licensed under a Creative Commons Attribution NonCommercial 4.0 License (CC BY-NC 4.0).

CC Copyright F. Gazzillo et al., 2017

Licensee PAGEPress, Italy

Research in Psychotherapy:

Psychopathology, Process and Outcome 2017; 20:153-155

doi:10.4081/ripppo.2017.278 the absence of any scientific evidence of its efficacy, is coming to an end.

However, a recommendation should be made to be very careful in not equating the empirical support of a given treatment with the sole presence of randomized controlled trials (RCTs) that show its efficacy. This would be a mistake from both an empirical and a theoretical perspective, as it runs the risk of throwing out the baby with the bathwater. In other words, endorsing a perspective according to which a specific treatment should be promoted or rejected on the sole basis of findings from RCT studies runs the risk of putting clinical science back almost twenty years from the current more advanced understanding of the efficacy, effectiveness, and usefulness of psychotherapy (Dazzi, 2006; Dazzi, Lingiardi, \& Colli, 2006; Leichsenring et al., 2016; Silberschatz, 2017). This would be a Pyrrhic victory: absolutizing RCT as the only method to evaluate psychotherapy might favor its social legitimacy in the short time, as a result of the assimilation of psychological treatments to medical treatments (i.e., to the kinds of treatment for which RCT represents the gold standard); yet, in the long run such an assimilation would involve the negation of the scientific specificity of psychological treatments, thus hampering rather than promoting the scientific development of effective psychological treatments.

From this standpoint, the document Psychotherapies for Anxiety and Depression: benefits and costs deserves appreciation for its political and cultural value, as an instrument to be used for dealing with institutional agencies - first of all, with public and private health agencies. However, several reflections are required in order to broaden its scope, and to establish a good enough platform for debating the topic with the wider community of scientists and practitioners interested in the development and validation of psychological and psychotherapeutic treatments.

The first comment we want to make is that clients and patients do not need to receive evidence-based treatments per se. Actually, what they need to receive are effective treatments. In other words, the effectiveness of a treatment must be differentiated from the method used to empirically support it. On the scientific and logical levels, it is a serious error to confuse how to prove something with 
what we actually need to prove (Kvanvig, 2003; Orr, 1992; Pope \& Vasquez, 2007). The lack of this distinction would imply the transformation of a specific and necessarily limited research methodology, RCT, into a normative parameter for institutional decisions. RCT is only one of several research designs useful for supporting the efficacy of a psychological treatment. It may be good for this goal, but it is not, and cannot become, an absolute normative framework. Moreover, RCT designs were first created for research on drugs (Bothwell \& Podolsky, 2016) and are based on the epistemological assumption that the randomization of participants in a study and the use of alternative treatments and/or placebo in the control group (or groups) allow the researchers to disentangle the specific effect of the targeted treatment from other potentially confounding variables. This strategy remains problematic in psychotherapy research for many reasons, and notably for the number of other potentially confounding variables, which in this specific case also include the effects of therapy moderators and process variables (and among them, the potential effects concerning the characteristics of the individual who provides the treatment and the problematic definition of a placebo treatment; see Kirsch, Wampold, $\&$ Kelley, 2016). Therefore, even for proving the efficacy and effectiveness of a treatment, RCTs are in the best of cases only a first step and their results are not always as conclusive as one would hope. For example, a small difference in the efficacy of two different treatments, measured in general with self-report questionnaires, may be statistically significant without pointing to any relevant difference in the level of psychological health and wellbeing of a patient in the real life. Similarly, a positive and significant result of an RCT concerning some specific dependent variables addressed in the RCT design can have no relevant meaning for the well-being and the clinical improvements of patients receiving that treatment.

Obviously, this is not to say that RCTs are meaningless for psychotherapy research. Rather, we are stressing here that the evidence-based approach of RCT studies is only a specific approach (i.e., a specific method with its inherent strengths and weaknesses) to the problem concerning how to verify the efficacy of a treatment, but it is not the goal of this process. Moreover, scientific research is a continuous effort to revise and improve our knowledge and its use, so identifying RCTs with the final solution to the problem of how to test and improve our treatment techniques could be misleading and might obstruct the advancement of science.

A second important point is that research designs such as RCTs have been very useful for giving a direction and establishing a basic standard for showing the efficacy of a psychological treatment, but they have not been, and are not, able to deepen the knowledge of how a psychological treatment works, which therapeutic factors work for which kind of patients, the processes of change in different kinds of patients and the most useful settings for the different patients and treatments. As underlined in a note on the original document, in fact, RCTs are useful but they are not the royal road to scientific knowledge in this field. Actually, their limitations, when implemented in psychotherapy research, are widely known (Westen, Novotny, \& Thompson-Brenner, 2004) - e.g., considering the psychopathology of patients who share basically the same diagnostic label to be virtually identical; not taking into adequate account the different co-morbidity patterns and personality styles and disorders; not considering the subjective meanings of the symptoms for the different patients; not taking into account the different preferences of the different patients in choosing the treatment they will receive (i.e., the randomization of the treatments); the use of uniform (manualized) forms of treatment, whereas in real clinical practice psychotherapies cannot but be delivered flexibly on the basis of various contextual factors. These features make psychological treatments proved by RCTs different from the ones delivered in real life and limit the generalizability and ecological validity of their results. Pointing out these limitations does not mean abandoning a scientific and empirical approach to research on the efficacy and effectiveness of psychotherapy, but strengthening the methodological and theoretical scope of psychotherapy research.

On the basis of these considerations, we think that we need to abandon the fetishism of RCTs and start considering them as one of several tools that we have, one of the possible research strategies that may be used in assessing the efficacy and effectiveness of psychotherapy. Moreover, when pursuing this goal, we cannot forget the contextual nature of the clinical exchange (Schimmenti \& Caretti, 2016) and the need to understand and theorize the dynamics (rarely explicit and often not immediately observable) which underlie the clinical phenomena of the psychotherapy process. We cannot forget the fact that a good clinical theory needs to be derived from clinical facts, but it also needs to make them understandable, to model them and to predict new facts. And in order to accomplish these goals, we need to take into account factors and functions which are beyond what it is immediately observable - something which is true in science in general (Salvatore, 2016).

From a theoretical perspective, we now know that psychotherapy works (American Psychological Association, 2013; Wampold \& Imel, 2015) - this is something which is beyond any doubt. What we still need to understand, however, is why and how it works, in particular in the specific contexts of its actual practice, which is a constitutive parameter of real clinical practice.

Several years ago, for many medical conditions it was possible to think that the practitioner, the relationship between the physician and the patient, and the context in which a drug was delivered, were irrelevant factors for the efficacy of the drug. Now we know that this is not the case for many psychotropic medications (Kelley, Kraft- 
Todd, Schapira, Kossowsky, \& Riess, 2014). The function and meaning of the therapist-patient relationship, of the therapist, as well as of the clinical setting are still more relevant for psychological treatments (Frank \& Frank, 1993; Lingiardi \& Colli, 2015). This means that we need more research on these psychological factors, so that the questions we have to ask now are quite different from the ones that can be investigated with RCTs: what kind of treatment is effective, for what kind of patient, with what kind of psychological strengths and difficulties, delivered by what kind of practitioner, in what kind of relationship and through what kind of setting? And in order to look for answers to these questions we need a better and deeper understanding of the processes in the clinical exchange (Gazzillo, Waldron, Genova, Angeloni, Ristucci, \& Lingiardi, 2014; Levy, Ablon, \& Kächele, 2012). So, we need better research projects, more sophisticated and nuanced data and better theories shaping the training of future practitioners.

\section{References}

Abbass, A., Kisely, S., Rasic, D., Town, J.M., \& Johansson, R. (2015). Long-term healthcare cost reduction with intensive short-term dynamic psychotherapy in a tertiary psychiatric service. Journal of Psychiatric Research, 64, 114-120. doi: 10.1016/j.jpsychires.2015.03.001

American Psychological Association (2013). Recognition of psychotherapy effectiveness. Psychotherapy, 50(1), 102109. doi: 10.1037/a0030276

Bothwell, L.E., \& Podolsky, S.H. (2016). The emergence of the randomized, controlled trial. New England Journal of Medicine, 375(6), 501-504. doi: 10.1056/NEJMp1604635

Cuijpers, P. (2017). Four decades of outcome research on psychotherapies for adult depression: an overview of a series of meta-analyses. Canadian Psychology/Psychologie canadienne, 58(1), 7-19. doi: 10.1037/cap0000096

Dazzi, N. (2006). Il dibattito contemporaneo sulla ricerca in psicoterapia. In N. Dazzi, V. Lingiardi, \& A. Colli (Eds.), La ricerca in psicoterapia. Modelli e strumenti (pp. 3-29). Milano: Raffaello Cortina.

Dazzi, N., Lingiardi, V., \& Colli, A. (Eds.) (2006). La ricerca in psicoterapia. Modelli e strumenti. Milano: Raffaello Cortina.

Frank, J.D., \& Frank, J.B. (1993). Persuasion and healing: a comparative study of psychotherapy. London: Johns Hopkins University Press.

Gazzillo, F., Waldron, S., Genova, F., Angeloni, F., Ristucci, C., \& Lingiardi, V. (2014). An empirical investigation of ana- lytic process: contrasting a good and poor outcome case. Psychotherapy, 51(2), 270-282. doi: 10.1037/a0035243

Kelley, J.M., Kraft-Todd, G., Schapira, L., Kossowsky, J., \& Riess, H. (2014). The influence of the patient-clinician relationship on healthcare outcomes: a systematic review and meta-analysis of randomized controlled trials. PLoS One, 9(4), e94207. doi: 10.1371/journal.pone.0094207

Kirsch, I., Wampold, B., \& Kelly, J.M. (2016). Controlling for the placebo effect in psychotherapy: Noble quest or tilting at windmills? Psychology of Consciousness: Theory, Research, and Practice, 3(2), 121-131. doi: 10.1037/cns0000065

Kvanvig, J.L. (2003). The value of knowledge and the pursuit of understanding. Cambridge, MA: Academic Press.

Leichsenring, F., Abbass, A., Gottdiener, W., Hilsenroth, M., Keefe, J.R., Luyten, P., \& Rabung, S. (2016). Psychodynamic therapy: a well-defined concept with increasing evidence. Evidence-Based Mental Health, 19(2), 64. doi: 10.1136/eb-2016-102372

Levy, R.A., Ablon, J.S., \& Kächele, H. (2012) (Eds.). Psychodynamic psychotherapy research. Evidence-based practice and practice-based evidence. New York, NY: Humana Press.

Lingiardi, V., \& Colli, A. (2015). Psychotherapeutic process and therapeutic alliance. In O.C.G. Gelo, A. Pritz, \& B. Rieken (Eds.), Psychotherapy research: General issues, Process and Outcome (pp.. ). New York, NY: Springer. doi: 10.1007/978-3-7091-1382-0

Orr, D.W. (1992). Ecological literacy: education and the transition to a postmodern world. New York, NY: Suny Press.

Pope, K.S., \& Vasquez, M.J.T. (2007). Ethics in psychotherapy and counseling: a practical guide (3rd ed.). San Francisco, CA: Jossey-Bass.

Salvatore, S. (2016). Psychology in black and white. The project of a theory driven science. Charlotte, NC: Information Age Publishing.

Schimmenti, A., \& Caretti, V. (2016). Linking the overwhelming with the unbearable: developmental trauma, dissociation, and the disconnected self. Psychoanalytic Psychology, $33(1), 106-128$.

Silberschatz, G. (2017). Improving the yield of psychotherapy research. Psychotherapy Research, 27(1), 1-13. doi: 10.1080/10503307.2015.1076202

Wampold, B.E., \& Imel, Z.E. (2015). The great psychotherapy debate. The evidence for what makes psychotherapy work. New York, NY: Routledge.

Westen, D., Novotny, C.M., \& Thompson-Brenner, H. (2004). The empirical status of empirically supported psychotherapies: assumptions, findings, and reporting in controlled clinical trials. Psychological Bulletin, 130(4), 631-663. doi: 10.1037/0033-2909.130.4.631 